\title{
Research and Implementation of Comprehensive Service System on Community Health Care
}

\author{
Hao Zou ${ }^{1, a^{*}}$, Guozhang Jiang ${ }^{1, b}$, Shuang Zhao ${ }^{1, c}$, Zhujun $\mathrm{Li}^{1, d}$, \\ Minghao Chen ${ }^{1, e}$ and Rong Chen ${ }^{1, f^{\prime}}$ \\ ${ }^{1}$ Wuhan University of Science and Technology, China \\ a1052427946@qq.com, ${ }^{\text {b whjgz@wust.edu.cn, }{ }^{c} 1529951757 @ q q . c o m,{ }^{d} 1617753062 @ q q . c o m, ~}$ \\ e1174013165@qq.com, ${ }^{\mathrm{f}} 171228487 @ q q . c o m$
}

\begin{abstract}
Keywords: Community medicine; Personalized medical services; Health forecasting; Intelligent Question and answering
\end{abstract}

\begin{abstract}
With the development of society and the improvement of living standards, the increase of the average life of residents, China has gradually entered the aging stage. Community health service has been more and more attention. In this paper, proposed a people-oriented, application of computer network, medical facilities and other methods, the different subjects of the integrated community, hospitals, patients of sound, efficient, convenient comprehensive service system on community health care based on analyzing the status quo of China's aging population and community medical service demand. In order to meet the needs of community residents, and to promote the comprehensive service on community health care procedures, systematic, standardized, user-friendly development objective.
\end{abstract}

\section{Introduction}

From the specific situation of the general trend of development of the population and aging population [1], China will enter a stage of population aging. In order to reforming rural health service system, the Party Central Committee and the State Council implemented a series of new policies under the new historical conditions. The community medical service project is one of the characteristics of policy, which is widespread concerned by community residents. With the needs of the community, a variety of community medical service institutions have emerged in succession at home and abroad, The British health system is known as the national health service system (NHS) [2], and American health care system, the market is the main role on the system, the government is auxiliary, Singapore is complementary advantages of various types hospitals, community hospitals play an important role, Belgium take medical and health institutions into the community, providing the service model of treatment and rehabilitation all services. Compared with abroad, our country's medical resources show a feature that a general lack and uneven distribution. This paper proposed a people-oriented, application of computer network, medical facilities and other methods, the different subjects of the integrated community, hospitals, and patients of sound, efficient, convenient comprehensive service system on community health care.

\section{Research Status}

With the rapid development of modern science and technology, computer network, high-end medical equipment and other advanced technology is rapidly entering modern medical [4]. In the modern family and community life, the organic combination of medical system and medical network [5], which is become a modern medical pattern certain way to turn to society and humanity. The modern medical mode is gradually change from the previous medical treatment is difficult and expensive to efficient, convenient and user-friendly in contemporary social ideology. In nowadays, some developed countries have adopted combined with its special national medical service system, in the United States, the private financing of the total financing of medical accounted for more than $53 \%$, which reflects the American medical service system to market as the main body, that is to establish the nature of civil private medical and insurance as the dominant, the characteristics is the 
government plays a guiding role. In recent years, with China's continuous improvement of people's living standards, community medical service is being paid more and more attention. The health level of community service in China has also been greatly improved [6]. Today, community health service has been quite considerable development, but there are also some shortcomings, mainly reflected that the overall resources is lack, existing resources use rate is low, high-end talent is lack, the overall network environment is not perfect and so on.

\section{Community Medical Service System}

The essence of community health service performance in not only need to face the complex needs of the patient, but also have efficient and fast reaction mechanism, and to adapt to the dynamic environment of social economy. This requires the community medical service system has diversified, comprehensive efficiency and resilience sufficient sound characteristics.

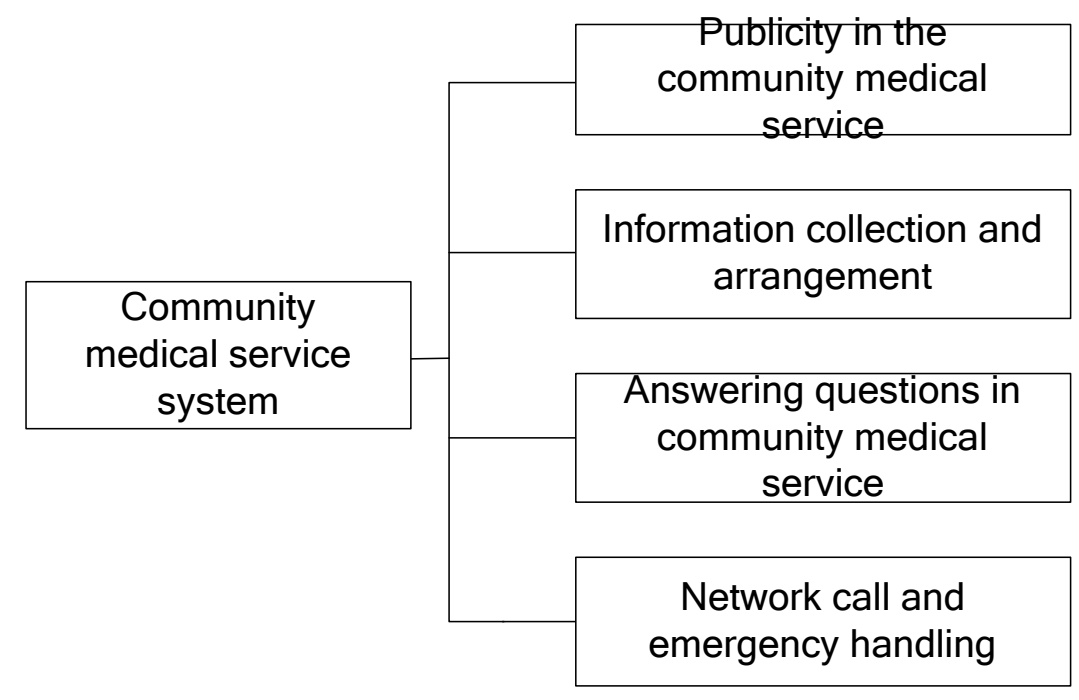

Figure 1. Community medical service

Community Health Services in Propaganda. People's living standard is increasing, and the increase in life expectancy, so people put more attention on personal health. Now people no longer like before as just disease to go to the hospital, actively carry out their own physical health care and disease prevention, but often lacking the corresponding professional medical knowledge and timely medical information, which need to establish a reasonable and efficient medical related publicity mechanism in the community. The specific implementation methods are as follows:

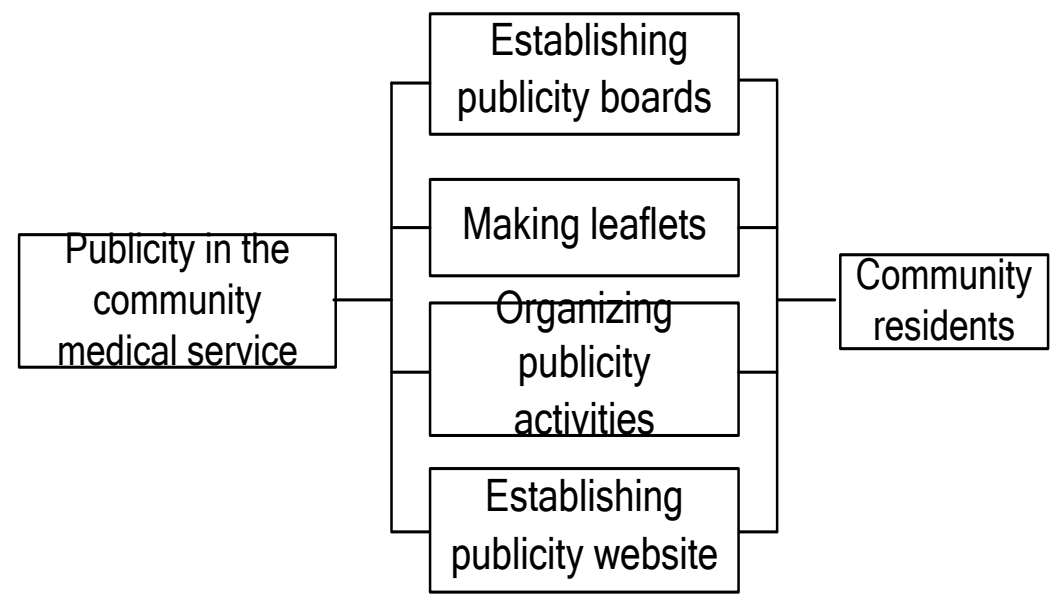

Figure 2. Publicity in the community medical service 
(1) Setting up specialized medical knowledge propaganda board in community main position, such as population is concentrated in the garden, Plaza, road junctions and other places, because the population of the community is relatively fixed, the advertisement propaganda can be effective into the integration of the lives of community residents.

(2) Making corresponding simple image publicity, considering the problem of community residents aging, some simple graphics and animation design combining publicity can be used, for example according to the different characteristics of each season, for the seasonal health promotion , community residents are more convenient to get information.

(3) In the community regularly organize relevant promotional activities, such as the 15th of each month, in community neighborhood committee organization to lectures, the theme of the conference forms of promotional activities, on daily body health care and disease prevention for publicity.

(4) Setting up the specialized community health promotion site. In today's science and technology explosion era, computer, mobile phone has been fully integrated into our life. the establishment of promotion website can be more efficient transmit a message to people. Website needs not only the timely and up-to-date medical information, but also the timely and effective delivery of information to the community residents. In addition, the website also needs to have the community medical service related information query, easy for community residents to better understand the community medical services.

Collection and Arrangement of Information in the Community Medical Service. Community medical services in the community, with effective publicity, it is required to have a certain feedback mechanism. After community residents have a certain medical awareness, community medical service center also has to accept the feedback of community residents. With feedback, community medical service centers can be more efficient to carry out the work. So as to form a benign circulation links from the community health service center to the community residents, community residents get the timely and effective service, community health service center to keep abreast of the needs of community residents.

In recent years, with the improvement of people's living standard, the average life expectancy increases, the total number of the aging population in our country is increasing gradually. Expected by the mid twenty-first Century, the elderly population will reach the highest peak in China [7], accounting for the proportion of the total population is expected to about $19 \%$, the total number of people may break 300 million. In the establishment of a community website, community health statistical analysis area and special effective user login mechanism are established. Setting up special user for the community residents, community residents can through a valid username and password to enter the area. In this region, the establishment of community residents' personal health records [8], community residents according to personal health, truthfully fill in personal health records, including community residents' image, personal health, treatment historical data and so on.

Community health service center after receiving the personal health records of community residents, according to personal health records data, the data were statistically analyzed. Specific circumstances in a more intuitive form, for example made of histogram, pie chart to display data, for community health service center medical staff browsing and querying. In order to achieve the goal of comprehensive and accurate data, the community medical service center should follow the information timely and accurately, and make the information corresponding to the individual.

Answering Questions in Community Medical Service. In the community medical service, the consultation question and answer [9] is an indispensable and important link, not only having great significance in improving the quality of medical treatment, but also reflected the human nature of community medical service. Nowadays, the network is highly developing, people can easily understand a lot of information on the network, such as a wide range of medical information, medical propaganda. But, the information on the network exist accuracy and usefulness problem for community residents. Because of the huge and complex network, the information is some inaccuracy on the network, some information may only be used for propaganda, does not necessarily conform to our reality. In addition, some information may be outdated; a large part of outdated information is not accurate. And for medical problems, the veracity is most important, 
because the medical treatment related to the health of the human body. In addition, some people do not often use the network, when there is a doubt or need to know the information, which may not be effective solution. Based on the above questions, the medical service center will need to provide accurate and effective consultation.

In the community medical service, the system adopts the flexible form of the combination of manual answering and network answering. The artificial question and answer link includes the email, the network independent discussion room, the community message board, the regular question and answer meeting and so on various forms to carry on. Network automatic question answering is to provide medical information knowledge base on community website. In view of the above questions, the community residents choose their own way according to their own situation. The combination of artificial question answering and automatic answering system is not only reflected in the artificial can timely and effective treatment of complex and changeable problems, but also reflects the characteristics of the network convenient and open. This will undoubtedly improve the community health service center's work efficiency, and the same time let the community realize humanization of community medical service.

Network Call and Emergency Treatment in Community Medical Service. At present, the computer network call system [10] is being used in the community medical service as a kind of high technology content service system. Network call system is to establish a network call server in the community medical service center, so that community residents can get timely and effective pre hospital first aid. Community health service center has established a network call system; it must establish a reasonable and effective emergency treatment mechanism of the corresponding. When the emergency occurs, the medical staff can quickly and accurately find the incident and timely dispatch. This requires the establishment of a direct connection between the community medical service center and the hospital. In the community medical service, the effective network call system not only can save the patient's life, but also can make the community residents realize the community caring and meticulous care.

\section{Conclusion}

Based on the modernization of the network and the aging of the community medical service system, it plays a positive role in promoting the integration of community health care program, systematization, standardization, and human development. Through further planning and adjustment, we can make the community health care more close to people's lives, more efficient for community residents. Community medical service publicity provides a variety of effective publicity for community residents. Through this way of publicity, community residents can timely understand the medical information. The function of information collection is to collect the feedback from the community residents to the community medical service center in community medical service. On the one hand, the community health service centers establish a reasonable health monitoring mechanism to grasp the personal health status of community residents. On the other hand, community residents to the community health service center to provide feedback to the health of individuals. Community medical service counseling can help the community residents to solve the problem. Answer mainly adopts the way of combination of manual answering and automatic answering. The role of network call and emergency treatment is to deal with the emergency situation of residents in community medical service.

\section{References}

[1] L.S Peng, W Zou: Analysis on the status quo and characteristics of the aging population in China. Industrial \& Science Tribune, Vol. 12(2013) No.11, p.7-8

[2] A.Z Hu, J.G Li: Characteristics of medical and health system in England and its reference to China. Soft Science of Health, Vol. 26(2012) No.2, p.84-85 
[3] J Li, H.Y Gao: The distributive justice of health care resources: whose justice? how to allocate? Medicine \& Philosophy, Vol. 36(2015) No.21, p.4-8

[4] D.Y Hu: Integrated medicine patient-centered care. Medicine \& Philosophy, Vol. 34(2013) No.9, p.1-4

[5] H F, E H: Technology, innovation and health equity. Bulletin of the Word Health Organization, Vol. 93(2015) No.7, p.438-438A

[6] Q.X Shi, Z Chen and H Zhu, et al: Present situation and suggestions of community medical service. Jiangsu Healthcare Administration, Vol. 21(2012) No.6, p.150-151

[7] Q Ying, L.T Han and Q.P Fang, et al: Survey on the needs of 2035 elderly people in community medical service. Zhejiang Journal of Integrated Traditional Chinese and Western Medicine, Vol. 22(2012) No.4, p.325-326

[8] K.X Wu, X Chen and Z.Y Zhai: Design and implementation of residents 'health records management system. Computer Applications and Software, Vol. 30(2013) No.4, p.214-216

[9] X Wang, L Yang and S.P Chen, et al: Development of a new telemedicine service mode. Shenzhen Journal of Integrated Traditional Chinese and Western Medicine, Vol. 20(2012) No.4, p.233-235

[10]L.L Jia, S.Y Li: MDA-based development and design for community E-services platform. Microcomputer Applications, Vol. 26(2010) No.8, p.15-17 